\title{
Morpho-Genetic Study and Detection of Boron Toxicity Tolerance of Wild Wheat Genotypes
}

\author{
Reza Mohammad Emon (Corresponding author) \\ Chinese National Center for Rice Improvement/State Key Laboratory of Rice Biology \\ China National Rice Research Institute (CNRRI) \\ No.28 Shuidaosuo Rd., Fuyang, Hangzhou, Zhejiang, 311400, P.R. China \\ Tel: 86-18758227131_E-mail: emonbina@yahoo.com \\ Plant Breeding Division \\ Bangladesh Institute of Nuclear Agriculture, Mymensingh- 2202, Bangladesh \\ Tel: 88-01558303056_E-mail: emonbina@yahoo.com
}

Adedze Yawo Mawunyo Nevame

State Key Laboratory of Rice Biology, China National Rice Research Institute (CNRRI)

No.28 Shuidaosuo Rd., Fuyang, Hangzhou, Zhejiang, 311400, P.R. China

Tel: 86-15068766752_E-mail: amen.nevame07@yahoo.fr

\author{
Perry J. Gustafson \\ Research Geneticist \& Professor of Genetics \\ University of Missouri, Columbia, Missouri 65211, USA \\ Tel: 001-573-882-7318 E-mail:pgus@missouri.edu
}

\author{
Md. Shahidul Haque \\ Department of Biotechnology
}

Bangladesh Agricultural University, Mymensingh- 2202, Bangladesh

Tel: 88-01716066503 E-mail: haquems@yahoo.com 


\author{
M. Jahiruddin
}

Department of Soil Science

Bangladesh Agricultural University, Mymensingh- 2202, Bangladesh

Tel: 88-01718813889_E-mail: m_jahiruddin@yahoo.com

\author{
Mirza Mofazzal Islam \\ Plant Breeding Division \\ Bangladesh Institute of Nuclear Agriculture, Mymensingh- 2202, Bangladesh
}

Tel: 88-01716280720 E-mail: mirza_islam@yahoo.com

Received: May 13, 2015 Accepted: June 8, 2015 Published: June 9, 2015

Doi: 10.5296/jab.v3i2.7600 URL: http://dx.doi.org/10.5296/jab.v3i2.7600

\begin{abstract}
The occurrence of boron toxicity becomes a major constraint in cereal production in the world, thus cause significant yield loss particularly in wheat, one of the most susceptible crops to boron toxicity. Development of tolerant variety is now of utmost importance since agronomic management of soil boron is becoming ineffective to mitigate the toxicity. Due to narrow genetic base of the existing wheat cultivars, genetic variation for this character was poorly reported. The present study was devoted to identify such variation by using two different genetic background of wheat including Aegilops and Triticum, which could be readily used in wheat breeding program. Morphological and genetic screening revealed that two species Ae. longissima and Ae. sharonensis expressed tolerance against boron toxicity. The molecular marker analysis such as unweighted pair group method and principal coordinate analysis confirmed these two species to be more tolerant to excessive boron with higher root length. Their derivatives genotypes TL-09 and TL-17 were found to explained considerable tolerance to boron. On other hand, among the SSR markers used, Xgwm192 was the most robust in identifying boron tolerance polymorphism. The diversity and variability observed in this work could open new avenue in developing B toxicity tolerant wheat variety.
\end{abstract}

Keywords: Boron-toxicity, Genetic diversity, SSR, Aegilops, Triticum, Root length, Cluster analysis

\title{
1. Introduction
}

Boron (B) is an essential micronutrient for plant growth and development. Crop production is hampered seriously under both conditions of deficient and excessive boron in the soil. Agronomic management of B toxicity is more of serious task than dealing with B deficiency (Sutton et al., 2007). Boron stress is one of the key limiting factors for crop production in 


\section{NI Macrothink}

many areas of the world (Jefferies et al., 2000). Agronomic management of B toxic soils is a robust practice (Sutton et al., 2007) and also, detoxification of excess B from soils. Development of wheat cultivars that are tolerant to B is the only long-term viable approach to deal with B toxicity and crop production (Schnurbusch et al., 2010). Wheat is very susceptible to B toxicity and production is hampered in toxic environments. Due to the stock of different genes in an interbreeding population used in breeding programs, the genetic diversity among wheat cultivars has decreased (Wei et al., 2000, as cited in Li et al., 2006). Hence, Wheat improvement programs require the inclusion of diverse genetic background as a source of target genes. Landraces, weedy species and wild relatives of wheat are generally the principal source of these genes ( $\mathrm{Li}$ et al., 2006). Aegilops, which is one of the most closely related genera of wheat, possesses tremendous genetic variability and could be the source of desirable B tolerant genes. Many other value-added genes of interest have been incorporated to cultivated wheat from Aegilops species (Schneider et al., 2008). In case of wheat, most of the earlier studies (Schnurbusch et al., 2008, Schnurbusch et al., 2007, Torun et al., 2006; Jefferies et al., 2000, Paull et al., 1992, 1991), for B toxicity tolerance, were conducted on bread wheat and durum wheat. The Aegilops genera are still neglected in B tolerance research, and the existence of such a large pool of genotypic variation is promising and can be used in wheat breeding programs for developing B-tolerant cultivars. So far only one report (Emon et al., 2012) is available which attempted to categorize the Aegilops species for B tolerance. Moreover, most of the previous studies (Konstantinos et al., 2010; Belkadi et al., 2011, Baghizadeh et al., 2011, Naghavi et al., 2009) that were devoted to identifying the genetic relationship and diversity of Aegilops species were based on RAPD markers. Previous studies were inappropriate in context of the number of species included and the type of molecular marker used for the diversity studies. On the other hand wild emmer wheat Triticum dicoccoides and rye (Secale cereale) are also important genetic stocks for improvement of cultivated wheat. Due to genetic similarities to cultivated wheat, the transfer of useful genes from these species is possible. Thus, the evaluation of genetic diversity of Aegilops, Triticum and rye could provide valuable information for genetic improvement of wheat. Therefore, in the present study 80 genotypes comprised of Aegilops, Triticum and rye species were subjected to a diversity study utilizing thirty-two SSR markers. The main objective of the study was to explore the genetic diversity and relationship of the species at the DNA level, and identify SSR markers linked to Boron toxicity tolerance.

\section{Materials and Methods}

\subsection{Plant Materials}

Seventy-nine genotypes from 12 wild species within the Aegilops-Triticum group were obtained from Dr. Moshe Feldman, Department of Plant Sciences, The Weizmann Institute of Science, Rehovot 76100, Israel. These genotypes were collected from several Mediterranean region sources (Table 1). One rye (Secale cereale 'Blanco') obtained from the USDA-Sears Collection; University of Missouri, USA was also included in this characterization.

\subsection{Hydroponic screening}

The hydroponic screening was done in a growth chamber with light set to $16 \mathrm{~h}$ day at $22{ }^{\circ} \mathrm{C}$ and $8 \mathrm{~h}$ night at $15{ }^{\circ} \mathrm{C}$. High quality seeds were sterilized in a solution of $1.3 \%$ sodium hypochlorite $(2.5 \%$ bleach solution) plus one drop of Tween 20 (surfactant) in distilled water 


\section{Macrothink}

for 8 minutes and then thoroughly rinsed. Seeds were placed on filter paper containing $0.2 \%$ of Pipracil (Piperacillin Sodium antibiotic) solution in labeled petri dishes for germination. Petri plates were shifted to a refrigerator $\left(4{ }^{\circ} \mathrm{C}\right)$ for adjusting seedling growth during germination. The hydroponic nutrient solution consisted of $0.4 \mathrm{mM} \mathrm{CaCl}_{2} ; 0.65 \mathrm{mM} \mathrm{KNO}_{3}$; $0.25 \mathrm{mM} \mathrm{MgCl}_{2} \cdot 6 \mathrm{H}_{2} \mathrm{O} ; 0.1 \mathrm{mM}\left(\mathrm{NH}_{4}\right)_{2} \mathrm{SO}_{4}$; and $0.04 \mathrm{mM} \mathrm{NH}_{4} \mathrm{NO}_{3}$ in dionized water (Yau, 2002). The nutrient solutions were supplemented with $\mathrm{H}_{3} \mathrm{BO}_{3}$ to make it at $3 \mathrm{mM}$ and $10 \mathrm{mM}$ of $\mathrm{B}$ concentrations. Four seedlings per accession with three replications were grown in $2 \mathrm{~L}$ of nutrient solution with 0,3 and $10 \mathrm{mM} \mathrm{B}$, respectively for 10 days. All genotypes were categorized as tolerant or susceptible based on their seedling root length.

Table 1. List of eighty Aegilops-wheat accessions collected from different country and used in SSR analysis of the present study

\begin{tabular}{|c|c|c|c|}
\hline Name of The Species & *Genome & Country & Name of the accessions \\
\hline \multirow{4}{*}{ Aegilops speltoides } & \multirow{4}{*}{$\mathrm{S}$} & Israel (7) & $\begin{array}{l}\text { TS-100, TS-02, TS-41, TS-43, } \\
\text { TS-47, TS-76, TS-01 }\end{array}$ \\
\hline & & Unknown (1) & TS-117 \\
\hline & & Turkey (1) & TS-118 \\
\hline & & Syria (1) & TS-132 \\
\hline \multirow[t]{2}{*}{ Aegilops longissima } & \multirow[t]{2}{*}{$\mathrm{S}^{1}$} & Israel (8) & $\begin{array}{l}\text { TL-01, TL-02, TL-04, TL-05, } \\
\text { TL-07, TL-09, TL-17, TL-21 }\end{array}$ \\
\hline & & Jordan (1) & TL-24 \\
\hline Aegilops sharonensis & $\mathrm{S}^{\mathrm{sh}}$ & Israel (9) & $\begin{array}{l}\text { ТН-17, ТН-02, ТН-03, ТН-04, ТН-07, } \\
\text { ТН-10, ТН-11, ТН-15, ТН-01 }\end{array}$ \\
\hline Aegilops bicornis & $S^{b}$ & $\begin{array}{l}\text { Israel (2) } \\
\text { Egypt (3) }\end{array}$ & $\begin{array}{l}\text { TB-04, TB-05 } \\
\text { TB-07. TB-10. TB-12 }\end{array}$ \\
\hline Aegilops searsii & $\mathrm{S}^{\mathrm{s}}$ & $\begin{array}{l}\text { Israel (4) } \\
\text { Syria (1) }\end{array}$ & $\begin{array}{l}\text { TE-03, TE-09, TE-21, TE-27 } \\
\text { TE-36 }\end{array}$ \\
\hline Aegilops kotschyi & US & Israel (6) & $\begin{array}{l}\text { TKK-01, TKK-03, TKK-06, } \\
\text { Tkk-11, TKK-27, TKK-21 }\end{array}$ \\
\hline Aegilops cylindrostachys & US & Israel (4) & TKC-01, TKC-04, TKC-06, TKC-08 \\
\hline \multirow[b]{2}{*}{ Aegilops euvariabilis } & \multirow[b]{2}{*}{ US } & Unknown (1) & TKE-02 \\
\hline & & Israel (9) & $\begin{array}{l}\text { TKE-03, TKE-12, TKE-19, TKE-22, } \\
\text { TKE-24, } \\
\text { TKE-42, TKE-46, TKE-62, TKE-66, }\end{array}$ \\
\hline Aegilops geniculata syn. ovata & $\mathrm{UM}$ & $\begin{array}{l}\text { Unknown (1) } \\
\text { Israel (2) }\end{array}$ & $\begin{array}{l}\text { TO-01 } \\
\text { TO-07, TO-13 }\end{array}$ \\
\hline
\end{tabular}


Aegilops biuncialis

Aegilops triuncialis

$\mathrm{UC}$

Israel (10)

Triticum. dicoccoides

Secale cereale

*Slageren (1994).

\subsection{DNA extraction}

Fresh leaves from 13-days old seedlings were used for DNA extraction followed by CTAB mini-prep method (IRRI, 1997). The DNA samples were analyzed both qualitatively and quantitatively using a spectrophotometer and $0.8 \%$ agarose gel electrophoresis.

\subsection{SSR marker genotyping}

Thirty-four selected SSR primers (along with three Barley primers) were used for the study. The majority of the primer pairs were selected from chromosomes 7B and 7D of wheat and $2 \mathrm{H}, 3 \mathrm{H}$, and $4 \mathrm{H}$ of barley, which are believed to be associated with the boron tolerance. Few primers were taken from wheat chromosomes, 5A, 5B, and 5D because recent study (Schnurbusch et al., 2008) identified some orthologous sequence of B tolerant genes on these chromosomes. The total PCR reaction volume was $13 \mu 1$, composed of $2.0 \mu 1$ genomic DNA, $1.5 \mu 1$ 10X PCR buffer (Tris with $15 \mathrm{mM} \mathrm{MgCl}_{2}$, Conc. 10×), $0.75 \mu 1 \mathrm{dNTPs}$ (Contains dCTP, dGTP, dTTP and dATP all in the conc. of $10 \mathrm{mM}), 1.0 \mu \mathrm{l}$ forward primer, $1.0 \mu 1$ reverse primer, $0.5 \mu \mathrm{l}$ Taq DNA polymerase (conc. $5 \mathrm{U} / \mu \mathrm{l}$ ) and $8.25 \mu 1$ sterille deionized water. Samples were subjected to the following thermal profile for amplification in a thermocycler: after the initial $7 \mathrm{~min}$ at $95^{\circ} \mathrm{C}$, SSR marker amplification comprised 10-15 touchdown cycles of $94{ }^{\circ} \mathrm{C}$ for $30 \mathrm{~s}$, annealing for $30 \mathrm{~s}$, decreasing the temperature by $0.5^{\circ} \mathrm{C}$ per cycle until the specified annealing temperature was reached, and $72{ }^{\circ} \mathrm{C}$ for $30 \mathrm{~s}$. This was then followed by 25-35 cycles of amplification with the specified annealing temperature, and a final extension at $72{ }^{\circ} \mathrm{C}$ for $10 \mathrm{~min}$. After amplification, the PCR tube was stored at $4{ }^{\circ} \mathrm{C}$ until electrophoresis. Visualization of amplification products was accomplished on a 3\% agarose gel in $0.5 \times$ TBE buffer. The agarose gels were stained with ethidium bromide solution for 20-25 min. The stained agarose gel was illuminated by UV-trans-illuminator and photographed for assessing the DNA profiles.

\subsection{Statistical Analysis}

The allele size at each microsatellite locus was measured in base pairs by using AlphaEaseFC 


\section{MInstitute Machin $^{m+1}$}

4.0 software (http://www.alphainnotech.com/software.htm: Alpha Innotech Inc.). The summary statistics including the number of alleles per locus, heterozygosity, gene diversity and polymorphism information content (PIC) values were calculated using Power Marker version 3.25 (Liu \& Muse, 2005). Power Marker was also used to generate a distance matrix based on Nei (Nei, 1972) distance. The genetic distance matrices were then subjected to the neighbor-joining method (Saitou and Nei, 1987) of tree formation. MEGA 5.0 (Tamura et al., 2007) was used to produce graphical trees. External validation (bootstrapping) of tree wherever performed was done by the program Phylip ver. 3.69 (Felsenstein, 2009) with 1000 permutation and co-phenetic correlation coefficient was calculated by NTSYSpc program ver. 2.11 (Rohlf, 2005) for internal validation of the phylogenetic tree. Principal coordinate (PCoA) and analysis of molecular variance (AMOVA) were performed by the program GENALEX ver.6.0 (Peakall and Smouse, 2006). Where not mentioned, software CONVERT ver. 1.31(Glaubitz, 2004) were used to convert the data in different format for the analysis of various software program.

\subsection{Correlation of Root Length and SSR Data}

Two dissimilarity distance matrixes were created with NTSYSpc software ver. 2.11 (Rohlf, 2005). The first matrix was produced from the standardized root length data using SIMINT procedure based on Average Taxonomic Distance (i.e. DIST coefficient in the procedure). Standardization of data was done by STAND procedure of NTSYS. The second matrix was generated with help of SSR data using Nei genetic distance (Nei, 1972). The allele frequency data from POWER MARKER was used to export the data in binary format (allele presence = " 1 " and allele absence $=$ " 0 ") for analysis with NTSYS-PC. Correlation between root length and SSR data were done by the mantel two-way matrix correspondence test (Mantel, 1967) with the help of MXCOMP procedure of NTSYS-pc. The significance of the correlation between the matrices was tested using the normalized Mantel $Z$-statistics.

\section{Results}

\subsection{Morphological Characterization}

\subsubsection{Root Length Variation}

In the hydroponic screening, variation in root length of the genotypes of each species under different concentrations $(0,3$ and $10 \mathrm{mM})$ is presented in the Figure 1. It was observed that many genotypes from Ae. speltoides, Ae. longissima, Ae. sharonensis, Ae. searsii, and Ae. euvariabilis exhibited good root length under the excess B concentrations. Whereas, Ae. geniculata, Ae. biuncialis, Ae. triuncialis, T. dicoccoides and S. cereale showed very poor root length with $0 \mathrm{mM}$ and $10 \mathrm{mM} \mathrm{B}$ concentration. But, surprisingly these species gave better root length under $3 \mathrm{mM} \mathrm{B}$. Among the species evaluated Ae. sharonensis, Ae. longissima and Ae. kotschyi revealed better tolerance against excess B than the other species (Figure 1). Ae. speltoides, Ae euvariablis and Ae. searsii also experience tolerance performance against B toxicity. Due to the inconsistency, no reliable conclusion can be drawn for any of the genotypes from the species Ae. kotschyi and Ae. bicornis. 


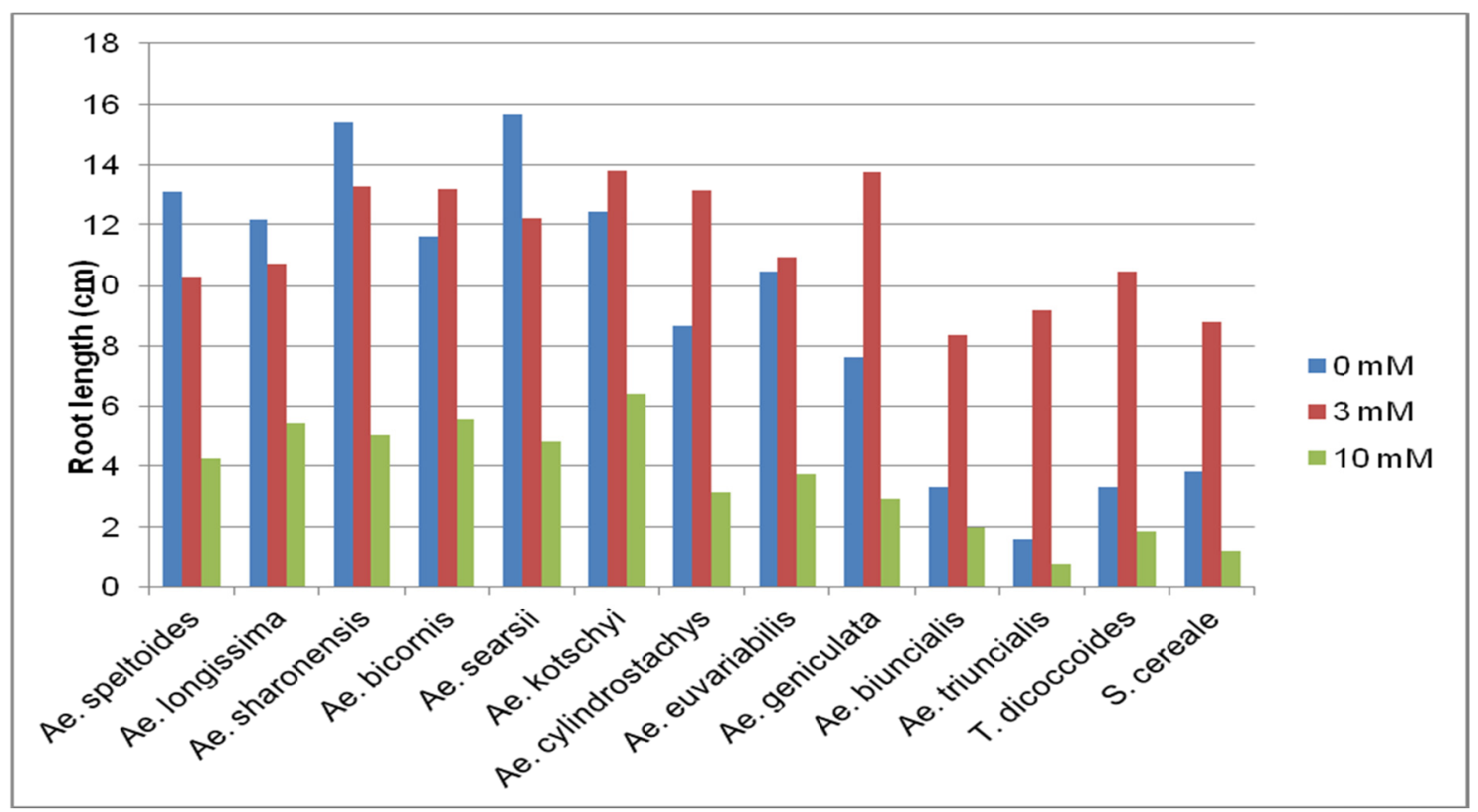

Figure 1. Tolerance of different species against different concentrations of Boron $(\mathrm{mM}=$ mili mole $)$

\subsection{Genomic Characterization with SSR}

\subsubsection{Genetic Variation within the Species}

In SSR based diversity analysis of eighty genotypes, a total of 265 alleles were identified utilizing thirty-four SSR makers. The number of alleles per locus ranged from 2 (Xgwm146 and Xgwm577) to 14 (Xgwm192) and average value of across all loci was 7.8. Marker WMC208 and WMC276 captured three alleles at each locus, which is also very close to the lowest value. The average heterozygosity over all the genotypes was 0.2 , with the maximum heterozygosity (0.786) being found at locus Xgwm642 and the minimum (0.025) at EBmac0679. Several loci (BARC182, Bmag0603, WMC208, WMC276, WMC537, Xgwm146, Xgwm158, and Xgwm577) did not show significant heterozygosity in the eighty genotypes studied. Marker Xgwm192 revealed the highest (0.893) gene diversity value and loci Xgwm577 revealed the lowest value (0.077), with a mean gene diversity of 0.65 over all markers. The PIC values varied from a low of 0.074 (Xgwm577) to a high of 0.883 (Xgwm192) with a mean of 0.61. Eight markers viz. BARC123, Bmac0093, WMC208, WMC276, Xgwm46, Xgwm146, Xgwm344, and Xgwm635 produced a PIC value lower than 0.5 . The results of all the diversity indices mentioned are presented in Table 2. 


\section{Macrothink}

Table 2. Allelic variation of the 34 SSR loci in the 79 wild wheat and one rye accessions

\begin{tabular}{|c|c|c|c|c|c|c|c|c|}
\hline $\begin{array}{l}\text { Sl. } \\
\text { No. }\end{array}$ & SSR marker & $\begin{array}{l}\text { Chr. } \\
\text { location }\end{array}$ & Repeat type & $\mathrm{T}\left({ }^{\circ} \mathrm{C}\right)$ & $\begin{array}{l}\text { Allele } \\
\text { no. }\end{array}$ & $\begin{array}{l}\text { Gene } \\
\text { diversity }\end{array}$ & $\begin{array}{l}\text { Hetero- } \\
\text { zygosity }\end{array}$ & PIC \\
\hline 1. & BARC10 & $4 \mathrm{~B}, 5 \mathrm{~A}, 7 \mathrm{~B}$ & $(\mathrm{GAA}) 13$ & 52 & 8 & 0.628 & 0.181 & 0.583 \\
\hline 2. & BARC32 & $5 \mathrm{~B}, 7 \mathrm{~B}$ & $(\mathrm{ATT}) 10$ & 52 & 11 & 0.855 & 0.144 & 0.842 \\
\hline 3. & BARC123 & $6 \mathrm{D}, 7 \mathrm{~B}$ & $(\mathrm{CA}) 9$ & 52 & 9 & 0.385 & 0.274 & 0.318 \\
\hline 4. & BARC182 & $7 \mathrm{~B}$ & (CT) 15 & 58 & 5 & 0.723 & 0.000 & 0.679 \\
\hline 5. & Bmac0093 & $2 \mathrm{H}$ & (AC) 24 & 55 & 7 & 0.460 & 0.111 & 0.396 \\
\hline 6. & Bmag0603 & $3 \mathrm{H}$ & (AG)24 & 55 & 6 & 0.698 & 0.000 & 0.660 \\
\hline 7. & EBmac0679 & $4 \mathrm{H}$ & (AC) 22 & 55 & 5 & 0.707 & 0.025 & 0.669 \\
\hline 8. & WMC31 & $1 \mathrm{~B}, 1 \mathrm{D}$ & (GT)19 & 61 & 7 & 0.734 & 0.130 & 0.688 \\
\hline 9. & WMC112 & $2 \mathrm{D}$ & $(\mathrm{CT}) 34$ & 61 & 9 & 0.802 & 0.423 & 0.776 \\
\hline 10. & WMC116 & $7 \mathrm{~A}$ & (CT) 12 & 61 & 8 & 0.723 & 0.098 & 0.674 \\
\hline 11. & WMC208 & $5 \mathrm{~B}$ & (GT)27 & 61 & 3 & 0.417 & 0.000 & 0.380 \\
\hline 12. & WMC245 & $2 \mathrm{~B}, 2 \mathrm{D}$ & $(\mathrm{CA}) 10$ & 61 & 10 & 0.819 & 0.242 & 0.795 \\
\hline 13. & WMC276 & $7 \mathrm{~B}$ & (CA)19 & 51 & 3 & 0.550 & 0.000 & 0.489 \\
\hline 14. & WMC296 & $2 \mathrm{~A}$ & (GT)28 & 61 & 6 & 0.712 & 0.303 & 0.667 \\
\hline 15. & WMC331 & $4 \mathrm{D}$ & $(\mathrm{CA}) 13$ & 61 & 12 & 0.694 & 0.473 & 0.671 \\
\hline 16. & WMC332 & $2 \mathrm{~B}$ & (CT) 12 & 61 & 12 & 0.818 & 0.220 & 0.797 \\
\hline 17. & WMC357 & $5 \mathrm{D}$ & (GT)10 & 61 & 11 & 0.781 & 0.394 & 0.763 \\
\hline 18. & WMC537 & $5 \mathrm{~B}, 7 \mathrm{~B}$ & (CT) 10 & 51 & 6 & 0.550 & 0.000 & 0.513 \\
\hline 19. & WMC581 & $7 \mathrm{~B}$ & $(\mathrm{GT}) 8$ & 61 & 8 & 0.732 & 0.285 & 0.688 \\
\hline 20. & Xgwm46 & $7 \mathrm{~B}$ & $(\mathrm{GA}) 2 \mathrm{GC}(\mathrm{GA}) 33$ & 60 & 8 & 0.318 & 0.300 & 0.309 \\
\hline 21. & Xgwm47 & $2 \mathrm{~A}, 2 \mathrm{~B}$ & (CT)7TT(CT)16 & 60 & 10 & 0.776 & 0.216 & 0.752 \\
\hline 22. & Xgwm146 & $7 \mathrm{~B}$ & $(\mathrm{GA}) 5 \mathrm{GG}(\mathrm{GA}) 20$ & 60 & 2 & 0.452 & 0.000 & 0.350 \\
\hline 23. & Xgwm192 & $5 \mathrm{D}$ & (CT)46 & 60 & 14 & 0.893 & 0.160 & 0.883 \\
\hline 24. & Xgwm193 & $6 \mathrm{~B}$ & (CT)24imp(CA)8 & 60 & 8 & 0.661 & 0.493 & 0.621 \\
\hline 25. & Xgwm264 & $1 \mathrm{~B}, 3 \mathrm{~B}$ & $(\mathrm{CA}) 9 \mathrm{~A}(\mathrm{CA}) 24$ & 60 & 7 & 0.734 & 0.142 & 0.693 \\
\hline 26. & Xgwm296 & $2 \mathrm{D}, 2 \mathrm{~A}$ & (CT)28 & 55 & 10 & 0.799 & 0.546 & 0.775 \\
\hline 27. & Xgwm344 & $7 \mathrm{~B}$ & (GT)24 & 55 & 9 & 0.455 & 0.112 & 0.395 \\
\hline 28. & Xgwm358 & $5 \mathrm{D}$ & $(\mathrm{GA}) 18(\mathrm{G}) 2(\mathrm{GA}) 4$ & 55 & 5 & 0.754 & 0.000 & 0.712 \\
\hline 29. & Xgwm471 & $7 \mathrm{~A}$ & (CA)34 & 60 & 10 & 0.726 & 0.268 & 0.695 \\
\hline 30. & Xgwm493 & $3 \mathrm{~B}$ & (CA)43imp & 60 & 10 & 0.816 & 0.071 & 0.793 \\
\hline
\end{tabular}




\begin{tabular}{llllllllll}
\hline 31. & Xgwm533.1 & 3B & $(\mathrm{CT}) 18(\mathrm{CA}) 20$ & 60 & 12 & 0.858 & 0.083 & 0.844 \\
32. & Xgwm577 & 7B & $(\mathrm{CA}) 14(\mathrm{TA}) 6$ & 55 & 2 & 0.077 & 0.000 & 0.074 \\
33. & Xgwm635 & 7A, 7D & $(\mathrm{CA}) 10(\mathrm{GA}) 14$ & 60 & 6 & 0.318 & 0.282 & 0.308 \\
34. & Xgwm642 & 1D & $(\mathrm{GT}) 14$ & 60 & 6 & 0.737 & 0.786 & 0.707 \\
Mean & & & & 7.794 & 0.650 & 0.199 & 0.617 \\
\hline
\end{tabular}

Additionally, species-wise analysis of various diversity parameters like allele number, effective allele number, heterozygosity, gene diversity, PIC, shanon information index and percent of polymorphic loci (Table 3) revealed that genotypes from Ae. ewvariabilis were the most diverse and those from Ae. biuncialis and Ae. triuncialis were least.

Table 3. Mean value of various diversity indices of different species

\begin{tabular}{llllllll}
\hline Species & AN & EAN & He & GD & PIC & SII & $\%$ P \\
\hline A. speltoides & 3.235 & 2.26 & 0.146 & 0.439 & 0.400 & 0.189 & $82.35 \%$ \\
A. longissima & 2.852 & 2.05 & 0.194 & 0.417 & 0.370 & 0.733 & $82.35 \%$ \\
A. sharonesis & 3.647 & 2.41 & 0.231 & 0.445 & 0.410 & 0.863 & $91.18 \%$ \\
A. bicornis & 2.529 & 1.93 & 0.189 & 0.393 & 0.346 & 0.672 & $79.41 \%$ \\
A. searsii & 2.558 & 2.03 & 0.221 & 0.402 & 0.352 & 0.689 & $85.29 \%$ \\
A. kotschyi & 2.882 & 2.30 & 0.182 & 0.485 & 0.426 & 0.834 & $91.18 \%$ \\
A. cylindrostachys & 2.323 & 1.95 & 0.220 & 0.398 & 0.344 & 0.651 & $79.41 \%$ \\
A. euvariabilis & 3.735 & 2.38 & 0.267 & 0.515 & 0.469 & 0.962 & $97.06 \%$ \\
A. geniculata & 2.352 & 1.90 & 0.237 & 0.407 & 0.347 & 0.662 & $85.29 \%$ \\
A. biuncialis & 1.441 & 1.40 & 0.176 & 0.227 & 0.186 & 0.311 & $44.12 \%$ \\
A. triuncialis & 1.823 & 1.62 & 0.225 & 0.276 & 0.230 & 0.455 & $64.71 \%$ \\
T. dicoccoides & 3.000 & 1.84 & 0.148 & 0.376 & 0.337 & 0.688 & $82.35 \%$ \\
Secale cereale & 0.735 & 0.73 & 0.041 & 0.352 & 0.345 & 0.041 & $5.88 \%$ \\
\hline A & $2.35 \%$
\end{tabular}

AN: Allele number; EAN: Effective allele number; He: heterozygosity; GD: genetic distance.

PIC: polymorphism informayion content; SII: Shanon information index; \% P: percent of polymorphic loci.

An UPGMA dendogram generated from the root length of different Aegilops-Triticum species have shown two major group clusters. The group-I contained only Ae. sharonensis was clustered distinctly from the remaining species with $100 \%$ of the bootstrap value. This species was found to produce comparatively higher root length and good tolerance to B toxicity. On other hand, the group-II was consisted of the other 12 species which were either sensitive or moderately sensitive to the B toxicity and exhibit a relatively reduced root length. 


\section{Macrothink}

For example the species $S$. cereale and $T$. dicoccoides that clustered togetther with very high $(99 \%)$ bootstrap value were sensitive to B toxicity. Three groups were observed, but interestingly, the more tolerant species Ae. speltoides, Ae. sharonensis and A. longssima coordinated together in group-III while the sensitive and moderately sensitive clustered in group-I and II. The grouping obtained by PCoA analysis agreed with the cluster analysis of both SSR and morphological data. An UPGMA tree with high value of co-phenetic $(r=0.71)$ produced from the root length of the 80 genotypes. All these genotypes were partitioned into six clusters and the means root length of each cluster were calculated under different concentrations of B (Figure $2 \& 3$ ). 


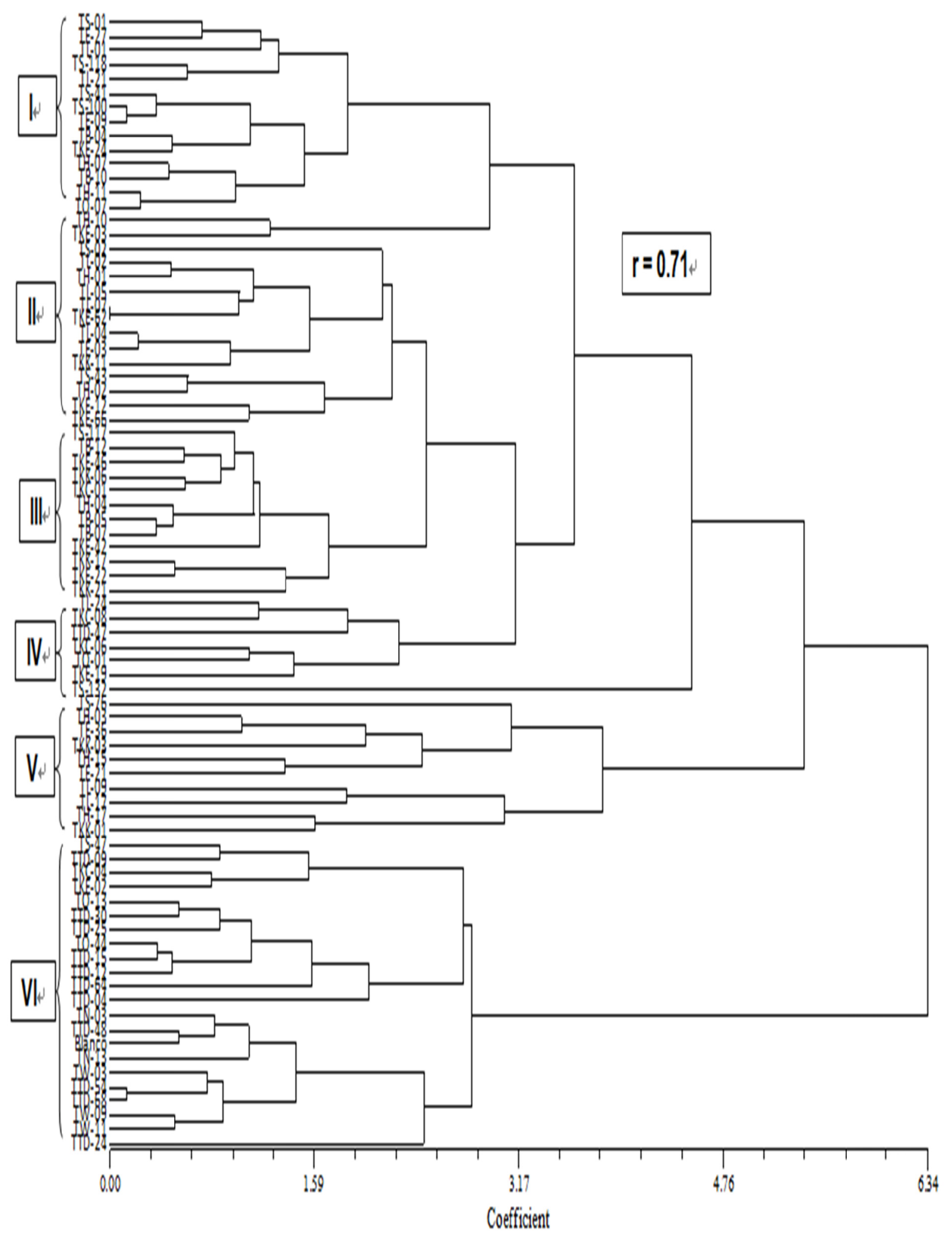

Figure 2. UPGMA Dendogram of 80 genotypes obtained from the root length data. I, II, III, IV \& VI are the different clusters 


\section{Macrothink}

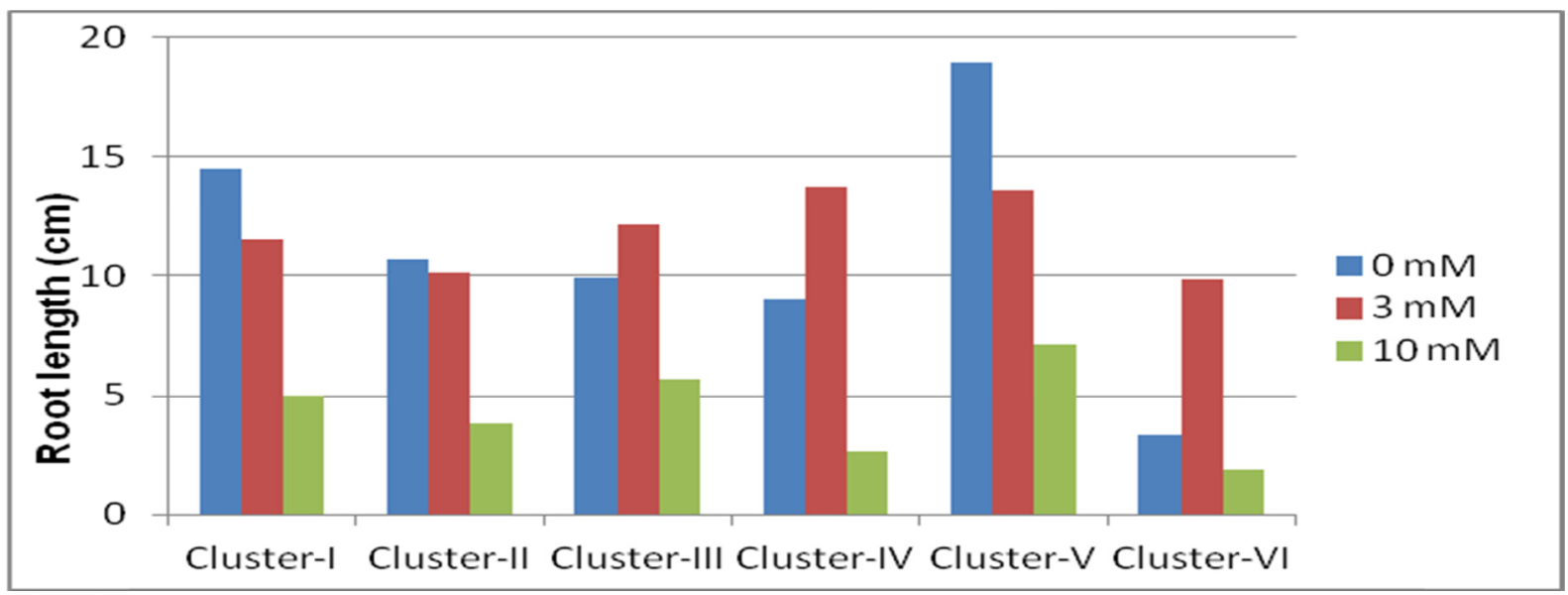

Figure 3. The mean of root length of genotypes obtained from different concentration of boron $(\mathrm{mM}=$ mili mole $)$ in each cluster

Cluster-VI included the boron sensitive genotypes with lowest mean value of root length. In contrast, the genotypes grouped in cluster- $\mathrm{V}$ have explained a good tolerance to boron toxicity and produced higher root length. The genotypes in other clusters showed medium root length. The neighbor-joining (NJ) tree produced from SSR data based on the Nei genetic distance separated all the genotypes into two major groups. The first major group and second major group showed the similar results as UPGMA for cluster-VI and V, respectively. The efficiency of the NJ tree was assessed by calculating the correlation value (r) between the original distance matrix and the co-phenetic matrix obtained from the dendogram. A high correlation value $(\mathrm{r}=0.81)$ between the matrixes indicated a good fit of the data set to the dendogram (Figure 4). 


\section{Macrothink}

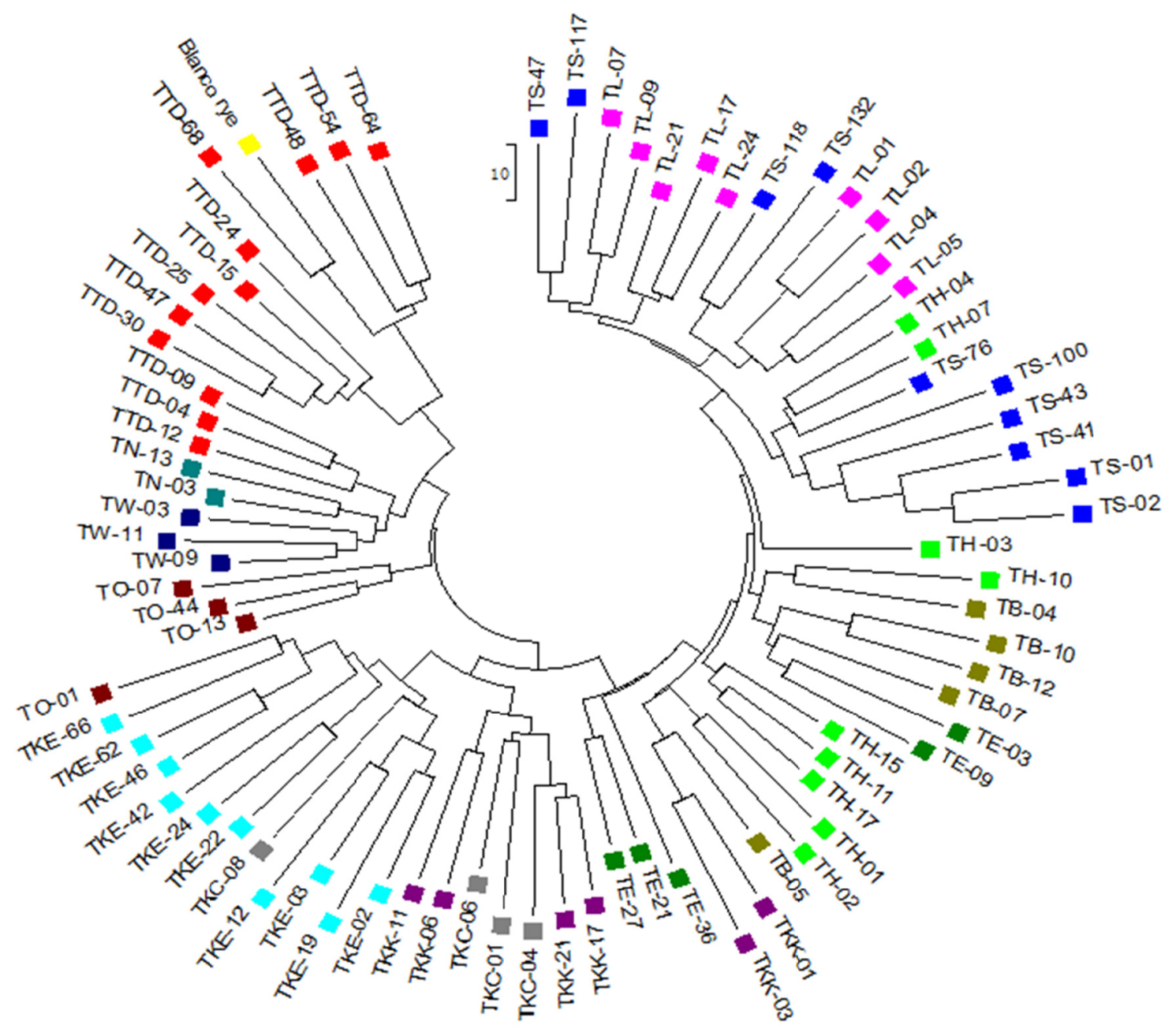

Figure 4. Neibour-Joining (NJ) tree generated from the SSR data showing the genetic relationship among genotypes of Aegilps-Triticum group

Conversely, the species Ae. longissima of the group-II displayed higher root length and good tolerance to B together with Ae. speltoides (Figure 5). In the comparison of pair-wise Fst values of the different species, also lowest value was observed between Ae. speltoides and A. longssima. AMOVA analysis showed that $28 \%$ of the total variation arose from different species and remaining $72 \%$ variation came from different genotypes within the species (Figure 6). In the principal coordinate analysis $70 \%$ of total variation accounted for the first three coordinates with the first coordinate demonstrating $34.48 \%$ variation while the second and third coordinates explained 20.91\% (Figure 7). 


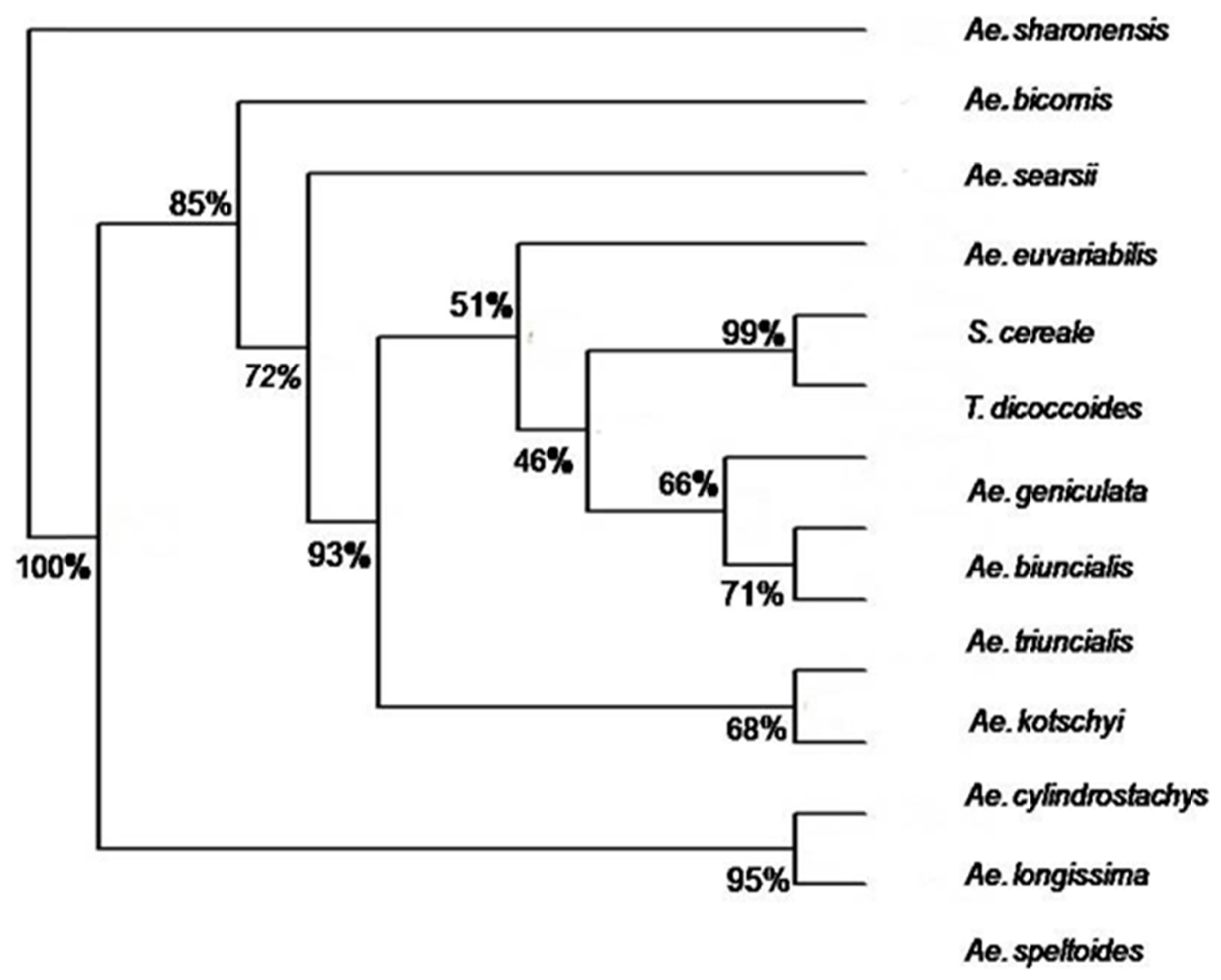

Figure 5. Cluster analysis based on SSR markers data of the Aegilops-Trticum complex.

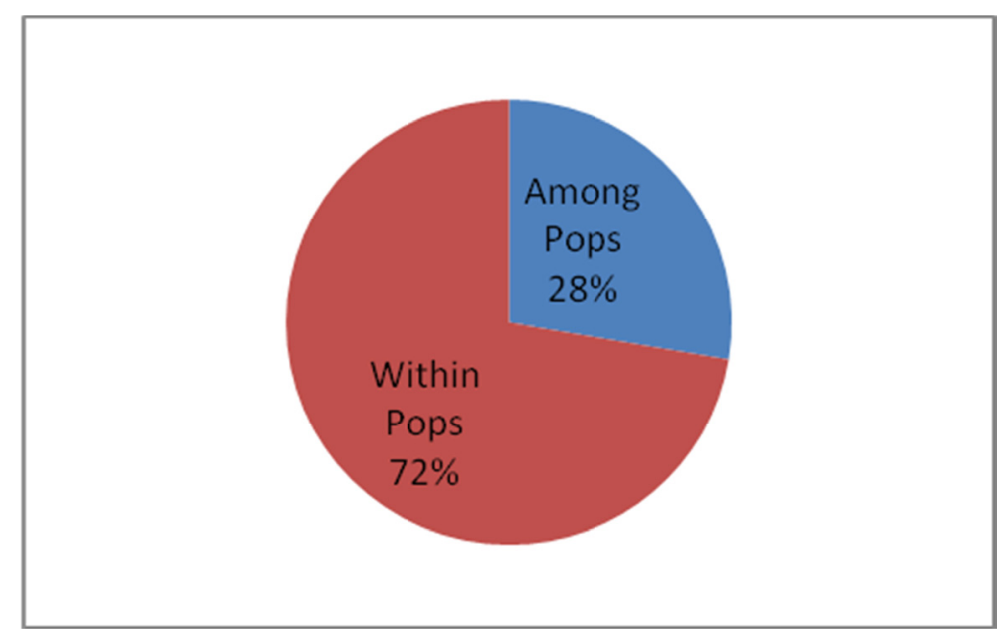

Figure 6. Genetic variation between Ae. speltoides and A. longssima populations (Pops). Blue color is the total variation from different species and Red color is the variation from different genotype within the species 


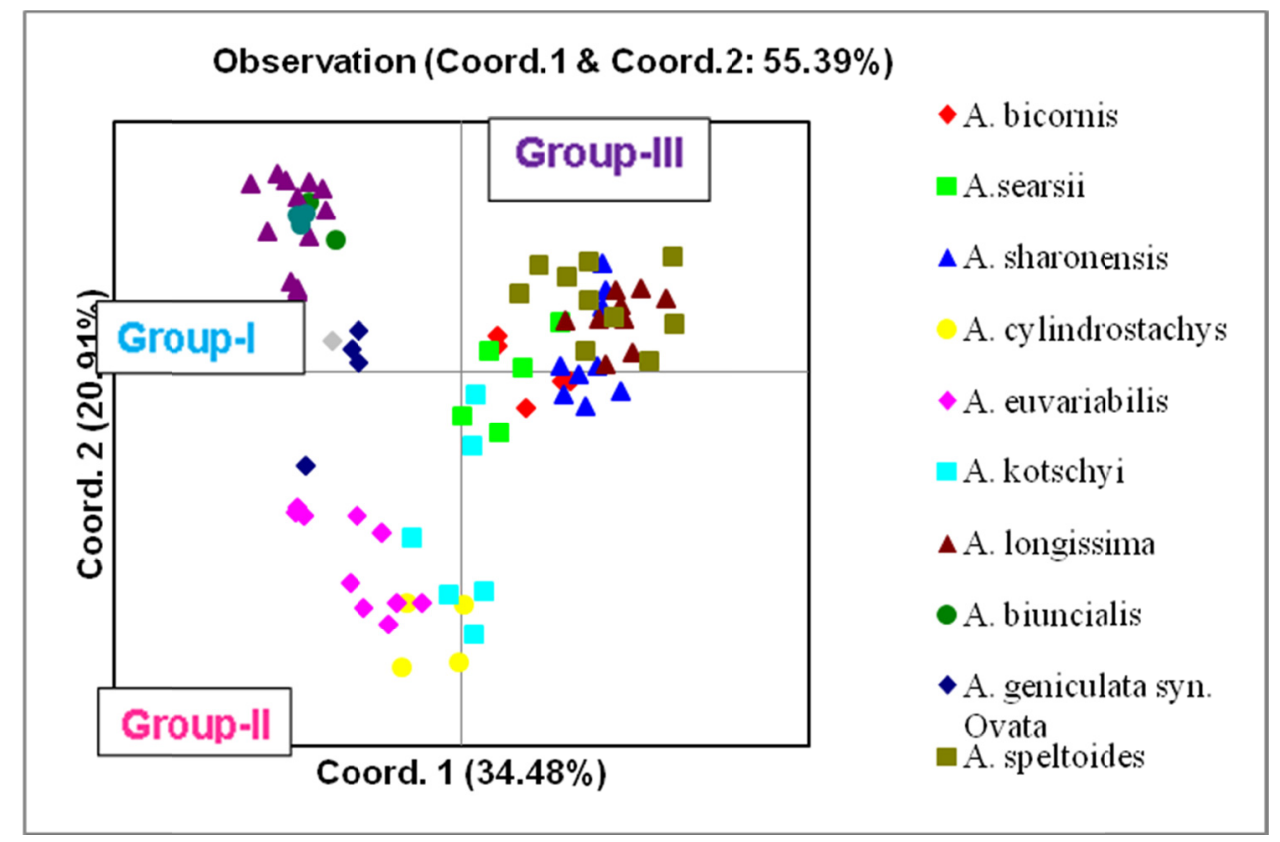

Figure 7. Result of the Principal Coordinate Analysis. Group I included Ae. geniculata syn. ovata, Ae. biuncialis, Ae. triuncialis and T. dicoccoides species with S. cereale (Blanco rye), group II contained Ae. kotschyi, Ae. cylindrostachys and Ae. euvaribilis and group III composed of Ae. speltoides, Ae. sharonensis, Ae. Bicornis, and Ae. Searsii

Correlation between root length and SSR data: The correlation between SiSR and root length data was assessed by Mantel matrix correspondence test. A positive significant correlation $(\mathrm{r}=$ $0.24, p=0.001$ ) was found but the value was low. Despite this low correlation, there were great similarities in separating the B sensitive genotypes from the B tolerant genotypes in the both dendrograms.

\section{Discussion}

Various Aegilops and Triticum species are very closely related to cultivated wheat. Historically, the utilization of these species for the improvement of wheat has achieved great success. In this study, a total of 80 genotypes including the cultivated wheat variety were grown under 3 treatments of B for evaluating their morpho-genetic characteristics and boron toxicity tolerance. Morphological screening of different species showed considerable variation for root length against B toxicity. Ae. sharonenesis is likely to express a similar tolerance as Aegilops longissima (Figure 1). Moreover, in the dendogram (Figure 2) generated from root length data, Cluster V (Figure 3) gave the highest mean root length and consisted mainly of the genotypes from Ae. longissima and Ae. sharonensis. The results found here agreed with the previous study (Emon et al., 2012), which identified these species as tolerant genotypes. In the cluster-V, two genotypes of Ae. longissima (TL-09 and TL-17) were grouped together (Figure 2), which was reported by Emon et al. (2012) as the most tolerant genotypes exhibiting very good root growth $(10.3$ and $10.9 \mathrm{~cm}$, respectively) under $10 \mathrm{~mm} \mathrm{~B}$ concentration. Moreover, variable response of some species (Ae. geniculata, Ae. kotschyi and Ae. euvariabilis) to B toxicity was observed (Figure 2). Causes of this variation may be explained by various factors such as endosperm development and quality, seed 


\section{NI Macrothink}

viability, seedling growth rate, and germination rate. Existence of such variation in seed between and within any Aegilops and Triticum species may be responsible for the non-uniform root growth observed in hydroponic screening (Figure 3). Therefore, sufficient care should be taken in hydroponic screening of any species. Regardless, this study suggests that some Aegilops species possesses significant tolerance to excess B and may be employed in wheat improvement programs for the development of B tolerant varieties.

In the DNA profiling of 80 genotypes by SSR markers, a total of 265 alleles were identified. The number of alleles per locus ranged from 2 (Xgwm146 \& Xgwm577) to 14 (Xgwm192) and averaged 7.8 (Table 2). The results were very similar to other studies (Bandopadhyay et. al., 2003; Sharma et al., 2002; Figliuolo \& Perrino, 2004). Average allele number/locus found was larger than previously reported by Ehtemam et al. (2010). The Aegilops-Triticum complexes used in the present study were collected from the different countries, which may have contributed to the high level of allelic diversity observed. The mean PIC value was 0.61 with a range from 0.075 to 0.883 (Table 2). The PIC value was much larger than earlier reported (Thomas et al., 2010; Naghavi et al., 2009) but were quite comparable to Bandopadhyay et al. (2003).

Considerable variation was observed among the genotypes for heterozgosity, which ranged from 0.025 to 0.786 with a mean of 0.2 (Table 2). Moreover, the lowest heterozygosity (0.14) was found in the genotypes of species Ae. speltoides and T. dicoccoides. The results suggest that the sample analyzed for these species was very narrow-based and that a larger gene pool needs to be evaluated. These species are closely related to wheat and very important for wheat improvement. Analysis of molecular variances (AMOVA) identified that maximum variation (72\%) existed among all genotypes of the species (Figure 6). Of the 34 markers, 26 (76\%) produced PIC values greater than 0.5 (Table 2). Marker Xgwm192 was the most robust in detecting polymorphisms. Moreover, except for Ae. biuncialis, Ae. triuncialis and $S$. cereale, in the remaining genotypes more than $80 \%$ loci were polymorphic (Table 3 ). This very high discrimination power of the SSR markers revealed their efficiency in depicting the genomic relationship and diversity of these Aegilops and Triticum complexes.

Species-wise analysis of different diversity statistics showed that the genotypes from $A e$. euvariabilis were the most diverse with $97.06 \%$ of the analyzed loci being polymorphic. Aegilops biuncialis and Ae. triuncialis genotypes were the least diverse species (Table 3). Moreover, in the UPGMA tree (Figure 4) the genetic relationship of the species studied, $A e$. sharonensis was placed in a separate cluster from the rest of the species with $100 \%$ bootstrap confidence. Its genome is closely related to cultivated wheat and has been reported as a rich source of biotic and abiotic stress resistance/tolerance genes, but is still not widely used in wheat improvement programs (Olivera \& Steffenson, 2009). Therefore, high tolerance to B toxicity and tremendous genetic variability observed in this species both by phenotypic and morphological data could help to draw the attention of wheat breeders for using this species in wheat improvement programs for B toxicity tolerance. In addition, it is evident from the dendogram that all the susceptible genotypes were placed in the same cluster. Also within this cluster $T$. dicoccoides and $S$. cereale were grouped together with a $99 \%$ bootstrap value. Aegilops geniculata, Ae. biuncialis and Ae. triuncialis were grouped in a single cluster. These findings are quite similar to other studies (Thomas \& Bebeli, 2010; Sallares \& Brown, 2004; 
Cenkci et al., 2008, Sasanuma et al., 2004). Furthermore, the close relation of S. cereale and $T$. dicoocoides may be the result of early introgression of organelle DNA of Aegilops-Triticum and Secale (Yamane \& Kawahara, 2005). But, this surprising relationship needs to be elucidated with further rigorous studies including a combination of different types of SSR markers and DNA sequence data.

On the other hand, both the dendrograms (obtained from root length, Figure 2 and SSR data, Figure 4 separated all eighty genotypes into two main groups according to B tolerance. Almost all the sensitive genotypes were clustered in the same group. Most of the markers used were selected from wheat chromosomes 7B and 7D of the wheat, and barley (Hordeum vulgare $\mathrm{L}$.) $2 \mathrm{H}, 3 \mathrm{H}$ and $4 \mathrm{H}$, which were previously reported (Jefferies et al., 1999, Jefferies et al., 2000, Paull et al., 1991) as the harboring chromosome of boron toxicity tolerance loci. Some markers were also selected from wheat chromosomes $5 \mathrm{~A}, 5 \mathrm{~B}$, and $5 \mathrm{D}$ because a recent study (Schnurbusch et al., 2008) identified B tolerant genes on these chromosomes. The present results identified tolerant and susceptible genotypes. However, we used only root length data for phenotypic screening of B toxicity tolerance. Although root length measurement provides quick screening other characters like grain yield, shoot B concentration, grain B content etc. should be considered in any screening experiment. Further extensive studies including an increased number of SSR markers from the B tolerant chromosomes and a larger genotype sample size of these species may yield additional sources of B tolerant genes.

\section{Conclusion}

Evaluating wheat germplasm pools for B tolerance at the seedling root growth stage, using hydroponics can be a useful technique, but careful selection of the seed within each accession is needed to prevent the vagaries of seed quality from influencing root growth in hydroponics. The present study established that several species including Ae. sharonensis, Ae. kotschyi, Ae. bicornis, Ae. kotschyi, Ae. peregrina ssp. cylindrostachys, Ae. peregrina ssp. euvariabilis, Ae. geniculta syn. ovata, and some Ae. longissima and $T$. dicoccoides contained accessions that were generally more B tolerant, and that there were major differences in B tolerance within the various Aegilops/Triticum species. Variation that occurs within wild cereal species involving differences in endosperm development and quality, seed viability, seedling growth rate, germination rate, etc. were all problems in getting uniform root growth under hydroponic growing conditions whether or not B was added to the hydroponics solution. Nevertheless, several wild Triticeae species expressed sufficient B tolerance to be considered as useful candidates for wheat improvement programs striving to produce B tolerant cultivars. The assessment of genetic diversity is an essential component in germplasm characterization and conservation. This study also identified several genotypes from the analyzed species, which are highly tolerant to B toxicity, and show considerable variation for B toxicity tolerance. The variability in the species analyzed could be readily employed in wheat improvement programs to develop B toxicity tolerant cultivars and genetic diversity at the DNA level could be used for designing effective breeding programs aiming to broaden the genetic bases of commercially grown varieties.

Funding: The work was supported by a grant from the United States Department of Agriculture (USDA) collaboration with the University of Missouri, Columbia, USA and 


\section{MInstitute Macrothink $_{\text {Int }}$}

Bangladesh Agricultural University, Mymensingh, Bangladesh.

Acknowledgement: The authors are thankful to Dr. Moshe Feldman, Department of Plant Sciences, The Weizmann Institute of Science, Rehovot 76100, Israel for kindly providing the Seventy-nine genotypes from 12 wild species within the Aegilops-Triticum group. The authors are also thankful to Dr. Henry T. Nguyen, Director, National Center for Soybean Biotechnology, Missouri Soybean Merchandising Council and Profesisor, University of Missouri, Columbia, USA (573) 882-5494 for his kind cooperation, suggestion and advice during conducting the research. We thank Mr. M.M. Hassan, Dept. of Genetics and Plant Breeding, Patuakhali Science and Technology University, Bangladesh for guidance in statistical analysis.

\section{Reference}

Baghizadeh, A., \& Khosravi, S. (2011). Genetic diversity assessment of aegilops germplasm by RAPD molecular markers. Agric Biol $J \quad N$ Am., 2, 197-202. http://dx.doi.org/10.5251/abjna.2011.2.2.197.202

Bandopadhyay, R., Sharma, S., Rustgi, S., Singh, R., Kumar, A., Balyan, H.S., \& Gupta, P.K. (2004). DNA polymorphism among 18 species of Triticum-Aegilops complex using wheat EST-SSRs. Plant Sci., 166, 349-356. http://dx.doi.org/10.1016/j.plantsci.2003.09.022

Belkadi, B., Assali, N., Filali-Maltouf, A., \& Benlhabib, O. (2011). Diversity analysis of Aegilops species from Morocco using RAPD markers. Genet Resour Crop Evol., 58, 271-282. http://dx.doi.org/10.1007/s10722-010-9570-8

Cenkci, S., Yildiz, M., Konuk, M., \& Eren, Y. (2008). RAPD analyses of some wild Triticum and Aegilops species and wheat cultivars in turkey. Acta Biol Craco S Bota., 50, 35-42.

Ehtemam, M. H., Rahiminejad, M. R., Saeidi, H., Tabatabaei, B. E. S., Simon, G., Krattinger, S. G., \& Keller, B. (2010). Relationships among the A Genomes of Triticum L. Species as Evidenced by SSR Markers. in Iran. Int. J. Mol. Sci., 11, 4309-4325. http://dx.doi.org/10.3390/ijms11114309

Emon, R. M., Gustafson, K., Bebeli, P. J., Jahiruddin, M., Haque, M. S., Ross, K., \& Gustafson., J. P. (2012). Screening Aegilops-Triticum Species for Boron Tolerance. Afr. J. Agric. Res., 7(12), 1931-1936.

Felsenstein, J. (2011). PHYLIP (Phylogeny Inference Package) version 3.69. Distributed by the author. Department of Genome Sciences, University of Washington.

Figliuolo, G., \& Perrino, P. (2004). Genetic diversity and intra-specific phylogeny of Triticum turgidum L. subsp. dicoccon (Schrank) Thell. revealed by RFLPs and SiSRs. Genet Resour Crop Evol., 51, 519-527. http://dx.doi.org/10.1023/B:GRES.0000024153.75636.6f

Glaubitz, J. C. (2004). CONVERT: a user friendly program to reformat diploid genotypic data for commonly used population genetic software packages. Mol. Eco. Notes., 4, 309-310. http://dx.doi.org/10.1111/j.1471-8286.2004.00597.x

IRRI. (1997). Rice Almanac. IRRI-WARDA-CIAT, Los Banos, Laguna, Philippines.

Jefferies, S. P., Pallotta, M. A., Paull, J. G., Karakousis, A., \& Kretschmer, J. M. (2000). Mapping and validation of chromosome regions conferring boron toxicity tolerance in wheat (Triticum aestivum L.). Theor Appl Genet., 101, 767-777. 
http://dx.doi.org/10.1007/s001220051542

Li, W., Zhang, D. F., Wei, Y. M., Yan, Z. H., \& Zheng, Y. L. (2006). Genetic Diversity of Triticum turgidum L. Based on Microsatellite Markers. Russian Journal of Genetics., 42, 311-316. http://dx.doi.org/10.1134/S1022795406030124

Liu, K., \& Muse, S. V. (2005). Power Marker: Integrated analysis environment for genetic marker data. Bioinformatics., 21, 2128-2129. http://dx.doi.org/10.1093/bioinformatics/bti282

Naghavi, M. R., Aghaei, M. J., Taleei, A. R., Omidi, M., Mozafari, J., \& Hassani, M. E. (2009). Genetic diversity of the D-genome in T. aestivum and Aegilops species using SSR $\begin{array}{lllll}\text { markers. Genet Resour Crop Evol., } & \text { 469-506. }\end{array}$ http://dx.doi.org/10.1007/s10722-008-9381-3

Naghavi, M. R., Hajikram, M., Taleei, A. R., \& Aghaei, M. J. (2010). Microsatellite analysis of genetic diversity and population genetic structure of Aegilops tauschii Coss. in Northern Iran. Genet Resour Crop Evol., 57, 423-430. http://dx.doi.org/10.1007/s10722-009-9481-8

Nei, M. (1972). Genetic distance between populations. Am. Nat., 106, 283-292. http://dx.doi.org/10.1086/282771

Olivera, P. D., \& Steffson, B. J. (2009). Aegilops sharonensis: origin, gemetics diversity and potential for wheat improvement. Bot., 87, 740-756. http://dx.doi.org/10.1139/B09-040

Paull, J. G., Nable, R. O., \& Rathjen, A. J. (1992). Physiological and genetic control of the tolerance of wheat to high concentrations of Boron and implications for plant breeding. Plant and Soil., 146, 251-260. http://dx.doi.org/10.1007/BF00012019

Paull, J. G., Rathjen, A. J., \& Cartwright, B. (1991). Major gene control of tolerance of bread wheat (Triticum aestivum L.) to high concentrations of soil boron. Euphytica., 55, 217-228. http://dx.doi.org/10.1007/BF00021242

Peakall, R., \& Smouse, P. E. (2010). GENALEX 6.0: genetic analysis in Excel. Population genetic software for teaching and research. Mol Ecol Notes., 6, 288-295. http://dx.doi.org/10.1111/j.1471-8286.2005.01155.x

Rohlf, F. J. (2005). Numerical taxonomy and multivariate analysis system. NTSYS version 2.11X. Applied Biostatistics Inc. New York.

Saitou, N., \& Nei, M. (1987). The neighbor-joining method: a new method for reconstructing phylogenetic trees. Mol Biol Evol., 4, 406-425.

Sallares, R., \& Brown, T. A. (2004). Phylogenetic analysis of complete 5 external transcribed spacers of the 18S ribosomal RNA genes of diploid Aegilops and related species (Triticeae, Poaceae). Genet Resour Crop Evol., http://dx.doi.org/10.1023/B:GRES.0000034576.34036.a1

Sasanuma, T., Chabane, K., Endo, T. R., \& Valkoun, J. (2004). Characterization of genetic variation in and phylogenetic relationships among diploid Aegilops species by AFLP: incongruity of chloroplast and nuclear data. Theor Appl Genet. 108, 612-618. http://dx.doi.org/10.1007/s00122-003-1485-8

Schneider, A., Molna,'R. I., Molna,'R-LA., \& 'Ng. A. (2008). Utilisation of Aegilops (goatgrass) species to widen the genetic diversity of cultivated wheat. Euphytica., 163, 1-19. http://dx.doi.org/10.1007/s10681-007-9624-y 


\section{Mll Macrothink}

Schnurbusch, T., Collins, N. C., Eastwood, R. F., Sutton, T., Jefferies, S. P., \& Langridge, P. (2007). Fine mapping and targeted SNP survey using rice-wheat gene: colinearity in the region of the Bol boron toxicity tolerance locus of bread wheat. Theor. Appl. Genet., 115, 451-461. http://dx.doi.org/10.1007/s00122-007-0579-0

Schnurbusch, T., Hayes, J., \& Sutton, T. (2010). Boron toxicity tolerance in wheat and barley: Australian perspectives. Breed Sci., 60, 297-304. http://dx.doi.org/10.1270/jsbbs.60.297

Schnurbusch, T., Hayes, J., Hrmova, M., Baumann, U., Ramesh, S. A., Tyerman, S. D., Langridge, P., \& Sutton, T. (2010). Boron toxicity tolerance in barley through reduced expression of the multifunctional aquaporin HvNIP2;1. Plant Physiol., 153, 1706-1715. http://dx.doi.org/10.1104/pp.110.158832

Schnurbusch, T., Langridge, P., \& Sutton, T. (2008). The Bo1-specific PCR marker AWW5L7 is predictive of boron tolerance status in a range of exotic durum and bread wheats. Genome., 51, 963-971. http://dx.doi.org/10.1139/G08-084

Sharma, S., Balyan, H. S., Kulwal, P. L., Kumar, N., Varshney, P. K., Prasadand, M., \& Gupta, P. K. (2002). Study of interspecific SSR polymorphism among 14 species from Triticum-Aegilops group. Wheat Inf Serv., 95, 23-28.

Sutton, T., Baumann, U., Hayes, J., Collins, N. C., Shi, B. J., Schnurbusch, T., ... Langridge, P. (2007). Boron-Toxicity Tolerance in Barley Arising from Efflux Transporter Amplification. Science., 318, 1446. http://dx.doi.org/10.1126/science.1146853

Tamura, K., Peterson, D., Peterson, N., Stecher, G., Nei, M., \& Kumar, S. (2011). MEGA 5: Molecular Evolutionary Genetics Analysis using Likelihood, Distance, and Parsimony methods. Mol Biol Evol., 28, 2731-2739. http://dx.doi.org/10.1093/molbev/msr121

Thomas, K. G., \& Bebeli, P. J. (2010). Genetic diversity of Greek Aegilops species using different types of nuclear genome markers. Mol Phylo Evol., 56, 951-961. http://dx.doi.org/10.1016/j.ympev.2010.04.041

Torun, A. A., Yazici, A., Erdem, H., \& Cakmak, I. (2006). Genotypic variation in tolerance to boron toxicity in 70 durum wheat genotypes. Turkish Journal of Agriculture and Forestry., 30, 49-58.

Yamane, K., \& Kawahara, K. (2005). Intra- and interspecific phylogenetic relationships among diploid triticum-aegilops species (poaceae) based on base-pair substitutions, indels, and microsatellites in chloroplast noncoding sequences. $A J$ Bot., 92, 1887-1898. http://dx.doi.org/10.3732/ajb.92.11.1887

Yau, S. K. (2002). Interaction of boron-toxicity, drought, and genotypes on barley root growth, yield, and other agronomic characters. Aust. J. Agric. Res., 53, 347-354. http://dx.doi.org/10.1071/AR00154

\section{Copyright Disclaimer}

Copyright reserved by the author(s).

This article is an open-access article distributed under the terms and conditions of the Creative Commons Attribution license (http://creativecommons.org/licenses/by/3.0/). 